\title{
Volume 2, Issue no. 3
}

\section{Active Ageing in the Nordic Countries: Introduction}

\author{
I Robert H Salomon
}

he year 2012 is designated as the European Year for Active Ageing and Solidarity between Generations. The aim of the year is to raise awareness of the position of older people in a manner where they can enjoy a better quality of life and still play an active role in society. There are good reasons for designating 2012 as such a year.

The OECD has estimated that by the year 2050, more than $33 \%$ of men and $38 \%$ of women in the EU25 will be 60 years or older compared with $18 \%$ and $24 \%$, respectively, for the year 2000. The European Statistical Office projects that by 2060, there will be only two people of working age (15-64) in the EU for every person aged over 65 , compared with a ratio of 4 to 1 today. Keeping in mind that an increasing share of the youth between 15 and 30 are studying, the consequences of these figures are even more challenging.

Many politicians are seriously concerned about financing of the pensions and welfare systems. Another concern is how to allocate sufficient healthcare personnel to give the ageing population a decent service. These challenges are good reasons for the EU to include "solidarity between generations" as an element in the activity of this year.

This special issue on active ageing is a contribution from the Nordic Journal of Working Life Studies to the year of active ageing. The articles examine work and ageing from different angles and horizons of understanding. Together, the articles question some of the myths that exist on ageing and work and assess some of the actions being taken to keep older workers in employment. This issue is therefore an important contribution to the development of our understanding of active ageing and measures used to develop an active ageing policy.

Almost all articles of this special issue deal with active ageing in the working life. However, in line with the policy of the journal, also special issues are open for articles on other topics. Therefore, we have also included articles dealing with topics other than active ageing in this issue.

The literature on active ageing in working life covers many aspects. We may distinguish between four main subjects of interest:

- Demography

- Individual attitudes and decisions

- The role of management and HRM practices at the workplace

- Public measures, legislation, and agreements 


\section{Demography}

The demographic facts as presented above are generally well known by policy makers. Demographic data are quite useful for forecasts. Many have seen the challenges of an ageing population for a long time, but most focus has been on the ratio between the income earning part of the population and the "dependent" one. Gradually, more attention has also been on the ageing workforce in working life. None of the articles in this issue deal with demography as the main theme, but demography is dealt with in introductions of several articles and is also an underlying factor of many of the themes treated in the articles.

\section{Individual attitudes and decisions}

Knowledge about peoples' conceptions of older workers' ability to work and older workers own conception of their own work capacity and motivation are important to understand the status of older workers and to look for measures to encourage them to stay longer in the workforce.

In the special Eurobarometer on active ageing (EU 2012), all the Nordic countries score relatively high on questions about satisfaction with their work. A high share of the respondents in the Nordic countries also feel that older people (55+) should play a major role in the economy. In general, it seems to be a positive attitude to older people in the Nordic countries compared with several countries in Southern and Eastern Europe. But according to the survey, around $20 \%$ of older people in the Nordic countries had directly or indirectly experienced discrimination concerning work. To sum up these observations: The Nordic countries are in a better position than many other European countries to contribute to active ageing in working life. But also these countries face some important challenges.

There is a lot of information available on individual attitudes and actions concerning retirement and extended working life. Health is important for decisions to leaving the labor force or to continue working. Decent health and reasonable work capacity are preconditions for an extended work career. Income is another important factor. Some older workers are in a financial position where they can choose between retirement and continued working career. Others, often women, are in a less favorable position. Due to low pensions, they are forced to continue working if they are able to do so. Working time and flexible working hours are also of importance. Another important factor is the feeling of being appreciated by colleagues and management.

Poor health, lack of economic incentives to continue to work, lack of flexibility in working hours, and discrimination are important factors bringing people out of working life.

Several of the articles include observations on attitudes among managers and colleagues to older workers. In her article, Kerstin Nilsson focuses on older workers' own attitudes to pension or extended working life. Her article is based on a qualitative study of older men living in rural areas in Sweden. She has studied men who already have left the labor market and men who continue working after the age of 65 .

In her article, she stresses that health and well-being are important factors for decisions on pensioning. Some of the respondents had experienced reduced health due to a hard and hazardous working life. Some respondents had also experienced how work 
actually contributed to keeping them active and contributed to avoid ill-health. The article reminds us that good active ageing policy should start early as part of the HRM policy (see, e.g., Salomon \& Hilsen 2011). She gives examples of how lack of, e.g., ear protection in noisy working environment early in the working career created health problems later.

The focus on health and well-being reminds us about the great contribution by Juhani Ilmarinen in the field of active ageing (see, e.g., Ilmarinen 2006). His work on workability and the Work Ability Index referred to by several articles in this issue is probably the most influential Nordic contribution in this field. His work has been read and applied in many European countries. His point of departure is that health and also the work capacity is reduced as people get older. To avoid or at least delay reduction of work capacity, it is necessary with preventive measures, e.g., physical training and training of the cognitive capacity. Nevertheless, most people will sooner or later reduce their workability. Then it is time to look for measures (and agreements) to reduce the work demand on older workers. By using a questionnaire, it is possible to assess the degree of workability for individuals and then identify the right measures for continued work.

The intention of Ilmarinen's work is quite positive and the workability index may function as a good instrument. But the underlying perspective is somewhat problematic. The point of departure of his thinking is that older people have reduced capacity, and the implication is that they are looked at as clients rather than resource persons.

In Norway, especially by the Centre for Senior Policy, the point of departure on active ageing is to stress the resources of the older workers. By underscoring the resource perspective, it is easier to look at older workers as an asset rather than as a burden. The challenge is to utilize the asset in a positive way.

The attitudes of older workers are important for their final decisions on retirement. But their attitudes are not formed in a vacuum. Nilsson reports that attitudes of others like spouse/partner, friends, and colleagues may influence decisions on retirement. Research by Rege et al. (2007) and others support the hypothesis that decisions to leave the labor market are influenced by attitudes among people in the local community by a form of snowball effect.

Another important observation by Nilsson is how introduction on control and reporting systems may lead to demotivation for an extended working career. One of the interviewed farmers expressed his feeling very well. His skills were in farming, not in reporting on production figures. Several school teachers reacted exactly in the same way when a lot of new teaching and reporting systems were introduced in the Norwegian secondary school some years back. They felt their tacit knowledge based on long working experience were not valuated any more and decided to leave the school (Hilsen \& Salomon 2010).

Kadefors and Hanse analyze the situation of older unemployed job seekers. Many of them experience that their skills, especially in ITC, are obsolete and not sufficient to meet the demand of today. Some of them also experience negative age-related attitudes among employers.

\section{The role of management and HRM practices at the workplace}

The other articles on active ageing in this issue deal with attitudes and actions of the management at the enterprise level. How are they thinking, and what are they doing 
concerning active ageing? These questions are quite important and dealt with at length in the articles.

Kadefors and Hanse stress the importance of training and competence development in their article. They report that the attitudes of managers toward older workers are mixed. They observe that attitudes among some managers are based not only on age stereotypes but also on functional experience. Managers express, e.g., that they are skeptical to the computer skills among older workers, a skepticism that actually is shared by older workers themselves when they assess their own competence.

They also observed that younger managers are more negative than older managers concerning the older workers' competence and flexibility to change.

Jensen and Møberg investigate as to what extent the serious challenge of an ageing population at the national level has any influence on attitudes and decisions made by individual employers in their HRM practice. About $70 \%$ of all Danish employers find that the ageing of the population represents an important challenge to society as a whole. However, employers are not especially concerned about active ageing policy to solve the challenges. They are in favor of early retirement arrangements and against increasing the age of retirement. Instead, the individual employers are interested in encouraging the Danes to have more children, to attract foreign labor, and to encourage part-time employees to work full time.

Jensen and Møberg present some interesting observations. Companies with greater share of employees over age 50 do have more knowledge of older employees and a greater tendency to include age management an integral part of the HRM policy in the company.

Pärnänen analyses four types of different age policies at workplaces in Finland. (1) In traditional industry companies, there has recently been a shift from early exit policies to policies to keep older workers longer by improving their working conditions. (2) In the public sector, it seems to be a policy to support older workers. However, in their HRM policy, they have to focus on recruiting young people in hard competition with the private sector. (3) Some service companies studied stressed age as a marketing factor. These service companies were based on part-time employment and directed toward younger customers. Thus they had a tendency to recruit younger employees. But they were aware of the benefits of middle-aged and older personnel servicing people in their age group. (4) A fourth group of companies studied were also in the service sector. In these companies, both hectic and strenuous work and the demand of new technological skill favored recruitment of young personnel. Thus ageing policies were not on the agenda.

Midsundstad et al. have studied to what extent special measures (so-called senior policy measures) at the workplace level actually have any effect on the retirement age of workers. By comparing retirement figures from workplaces with an active senior policy and workplaces without such a policy, they could not find any significant difference in retirement figures between the two groups of workplaces. There was a slight increase of the pension age in both groups during the period studied, but this increase may be due to other factors than the specific workplace measures in force.

The result of this study is not very supportive of an active senior policy at the workplace level. But several studies have demonstrated that such active senior policy measures at the workplace is very well received by the workers and may contribute to some positive years at the end of a long working career. 
Mykletun et al. have studied the beliefs and attitudes of public sector managers regarding measures to promote active ageing policies at the workplace. According to their survey, the interviewed managers believe in reducing working hours and annual working days, reducing workload and demand, giving economic incentives, increasing the esteem and learning opportunities, and improving the job content of older workers.

It is interesting to note that managers who are planning their own early retirement and reduced workload are less likely to believe in senior policy measures. Female and older managers seem to have a stronger belief in senior policy measures than younger managers.

Are the Nordic countries, and especially Norway, in a very special situation compared with most other countries concerning the conditions for an active ageing policy? The answer is probably yes since especially Norway overcame the financial crises so fast. Solem has analyzed data from an annual survey of managers (the Norwegian Senior Policy Barometer) over several years. He reports that older workers are among the least popular category of workers to recruit, independent of the status of the economy of the country.

Based on survey data over several years, he reports that there was a decline in the support of recruiting older workers just after the financial crisis, but when the Norwegian economy returned to normal, the support of recruiting older workers returned to the figures from before the crisis. The attitudes of managers in the private sector were more influenced by the crisis than attitudes of managers in the public sector.

\section{Public measures, legislation, and agreements}

In several countries, governments, employers' federations, and unions play an active role in active ageing policies. Attitudes and actions of both employers and employees will also be influenced by national policies, as, e.g., pension systems, tax systems, and general labor laws. New pension systems and national active policies are only briefly described in some of the articles in this issue. Therefore, we will make some comment on this topic below.

Legislation, national policies, and national and local agreements between the social parties will influence active ageing in working life. One important political decision of great importance will be the pension systems. A general trend in many European countries is to increase the pension age. Pension systems are revised with the aim of keeping people longer in the workforce. An intention of the new pension systems is to make it financially beneficial for people to continue working. Research findings on the impact of the new pension systems will be available in a few years time, and we hope to come back to this question in later issues of the journal.

One important shortcoming of several of the studies reported in this issue is the tendency to map which measures are most powerful and then rank them. In my opinion, too little attention is on the combined effect of the measures. Offering, e.g., economic incentives and reduced working hours has a side effect of announcing a positive recognition of older workers. A workplace offering a blend of measures may be more successful than enterprises just focusing on single measures.

In sum, this special issue lacks more data and discussions on how the various measures at the national level and local level interact. Is it possible to tighten the gap 
between the awareness of the demographic challenge at the macro level and local effort to deal with this challenge?

One of the ideas with this journal is to enable Nordic researchers to learn about each other and from each other. We hope that NJWLS will contribute to more exchange of views and more mutual learning among Nordic researchers in this field.

Editor of this special issue is Robert Salomon. Coeditors: Jan Ch Karlsson and Satu Kalliola.

\section{References}

Hilsen AI, Salomon R, et al. (2010) Seniorpolitikk—virker virkemidlene? (Senior Policy-Do the Measures Work?) AFI-rapport 4/2010. Oslo Arbeidsforskningsinstituttet.

Salomon RH \& Hilsen A I (2011) "A three phase perspective on senior policies" in Ennals R \& Salomon RH (eds) Older Workers in a Sustainable Society. Frankfurt am Main: Peter Lang Verlag.

EU (2012) Standard Eurobarometer 77 http://ec.europa.eu/public_opinion/index_en.htm

Ilmarinen J (2006) Toward a longer Working Life: Ageing and Quality of Working Life in the European Union. Helsinki: Finnish Institute of Occupational Health.

Rege M, Telle K \& Votruba M (2007) "Social Interaction Effects in Disability Pension Participation: Evidence from Plant Downsizing”, Research Department, Statistics Norway, Discussion Papers No. 496. 